Haider Ali*, Sofia Zhu and Jannike Solsvik

\title{
Effects of geometric parameters on volumetric mass transfer coefficient of non-Newtonian fluids in stirred tanks
}

https://doi.org/10.1515/ijcre-2021-0210

Received August 10, 2021; accepted November 13, 2021; published online November 23, 2021

\begin{abstract}
Scaling up stirred tanks is a significant challenge because of the research gaps between laboratory and industrial-scale setups. It is necessary to understand the effects of scale-up on the mass transfer in stirred tanks, and this requires meticulous experimental analysis. The present study investigates the effects of tank size and aspect ratio $\left(H_{L} / T\right)$ on the volumetric mass transfer coefficients of shear-thinning fluids. The experiments were conducted in three stirred tanks of different sizes (laboratory and pilot scale) and geometries (standard and nonstandard). $H_{L / T}$ was 1 for the standard tanks and 3.5 for the nonstandard stirred tanks. Three sizes of stirred tanks were used: $11 \mathrm{~L}$ with $H_{L / T}$ of $1,40 \mathrm{~L}$ with $H_{L} / T$ of 3.5 , and $47 \mathrm{~L}$ with $H_{L / T}$ of 1 . Impeller stirring speeds and gas flow rates were in the range of $800-900$ rev $\mathrm{min}^{-1}$ and $8-10 \mathrm{~L} \mathrm{~min}^{-1}$, respectively. The volumetric mass transfer coefficient was estimated based on the dissolved oxygen concentration in the fluids, and the effects of rheology and operating conditions on the volumetric mass transfer coefficient were observed. The volumetric mass transfer coefficient decreased as tank size increased and increased with an increase in operating conditions, but these effects were also clearly influenced by fluid rheology. The impacts of scale-up and operating conditions on the volumetric mass transfer coefficient decreased as liquid viscosity increased.
\end{abstract}

Keywords: aspect ratio; rheology; stirred tank; tank size; volumetric mass transfer coefficient.

\footnotetext{
*Corresponding author: Haider Ali, Department of Chemical Engineering, Norwegian University of Science and Technology, Trondheim, N0-7491, Norway, E-mail: haider.ali@ntnu.no. https://orcid.org/0000-0001-5610-4499
}

Sofia Zhu, Politecnico di Milano, Piazza Leonardo da Vinci, 32, 20133 Milan, Italy

Jannike Solsvik, Department of Chemical Engineering, Norwegian University of Science and Technology, Trondheim, NO-7491, Norway

\section{Introduction}

Scaling up stirred tanks in the presence of non-Newtonian fluids is highly challenging because of difficulties in translating the mass transfer process from the laboratory to the industrial scale. Fluid rheology, geometric parameters, and gas-distribution system are among the factors that control gas-liquid mass transfer rate in a stirred tank. Volumetric mass transfer coefficient $\left(k_{L} a\right)$ is a standard parameter to characterize mass transport by correlating the mass transfer rate to concentration change (García-Ochoa and Gómez 1998; Garcia-Ochoa and Gomez 2004). $k_{L} a$ must be known to design and scale-up stirred tanks. Dynamic (Bandyopadhyay, Humphrey, and Taguchi 1967) and steady-state (Imai, Takei, and Matsumura 1987) methods are generally used to measure $k_{L} a$ in stirred tanks. Dynamic methods (Bandyopadhyay, Humphrey, and Taguchi 1967) begin with deoxygenating the given liquid by using nitrogen. The cleaned air is then passed through the liquid, and a change in the dissolved oxygen (DO) concentration is recorded. $k_{L} a$ is estimated by fitting the transient curve of the DO concentration to an unsteady-state mass balance model. Dynamic methods (Bandyopadhyay, Humphrey, and Taguchi 1967) assume that there are well-mixed dispersed gas and liquid phases in the stirred tank, which is valid for small-scale reactors but not for large vessels, where achieving well-mixed gas and liquid phases is not always possible. Thus, large deviations in $k_{L} a$ measurements are expected when using dynamic methods (Bandyopadhyay, Humphrey, and Taguchi 1967) in largescale reactors (Dunn and Einsele 2007). Additionally, the time response $\left(\tau_{p}\right)$ of $\mathrm{O}_{2}$ sensors poses a problem with dynamic methods (Bandyopadhyay, Humphrey, and Taguchi 1967) when the $\tau_{p}$ is higher than the characteristic time of mass transfer $\left(1 / k_{L} a\right)$. Another concern about applying the dynamic method to viscous non-Newtonian fluids is the appearance of tiny gas bubbles suspended in such liquids. The contribution of these microbubbles to $k_{L} a$ is significantly smaller than that of large bubbles owing to low driving force (Muller and Davidson 1992; Shetty, Kantak, and Kelkar 1992). Thus, microbubbles are considered perfectly mixed, and their effect on $k_{L} a$ is mostly 
neglected (Gabelle et al. 2011; Heijnen, Riet, and Wolthuis 1980). Steady-state methods (Imai, Takei, and Matsumura 1987) require a chemical or biochemical reaction occurring in the liquid to reduce the DO concentration below the saturation level. $k_{L} a$ is then estimated by interpreting the recorded DO concentration with a steady-state mass balance model. The use of a chemical in steady-state methods can strongly affect $k_{L} a$. Moreover, steady-state methods are prone to errors, and a large error of nearly $\pm 100 \%$ can occur if measurements are not conducted correctly. Therefore, steady-state methods are not recommended for large-scale reactors and viscous fluids because of related issues to their cost, accuracy, and validation (Gogate and Pandit 1999; Linek, Beneš, and Vacek 1989).

Geometric parameters (e.g., size and aspect ratio of tank) play a decisive role in scaling up stirred tanks because of their direct influence on $k_{L} a$. Oxygen transfer due to surface aeration contributes nearly $50 \%$ of $k_{L} a$, especially in small tanks. Surface aeration decreases with increase in tank size that consequently reduces $k_{L} a$ (Humphrey 1998). The aspect ratio of the stirred tank, defined as the ratio of liquid height to tank diameter $\left(H_{L / T}\right)$, can be varied according to the application area. For instance, stirred tanks with the standard geometry $\left(H_{L / T}=1\right)$ are extensively used in the chemical industry. Standard stirred tanks have low construction costs and usually operate with a single impeller. Conversely, stirred tanks with a non-standard geometry $\left(H_{L / T}>1\right)$ are preferred for bioprocess applications, such as aerobic fermentation. $H_{L / T}$ of non-standard stirred tanks used in bioprocesses is suggested to range within 2-5 (Doran 2013). A higher $H_{L / T}$ provides larger residence time to gas bubbles, which increases $k_{L} a$ by improving oxygen solubility. Non-standard stirred tanks are equipped with multiple impellers to provide decent gas dispersion. Experimental studies on standard stirred tanks are extensive, but those on non-standard stirred tanks are limited, especially with non-Newtonian fluids. The authors also recently estimated $k_{L} a$ in standard stirred tanks with working volumes of 11 (Ali and Solsvik 2020) and $50 \mathrm{~L}$ (Ali and Solsvik 2021). A detailed literature review of standard stirred tanks has been carried out by Nere, Patwardhan, and Joshi (2003), Grenville and Nienow (2003), and Jaszczur and Młynarczykowska (2020). However, this work focused on a non-standard stirred tank in the presence of non-Newtonian fluids. Studies on $k_{L} a$ measurement in non-standard stirred tanks with non-Newtonian fluids are reviewed and summarized in Table 1.

A limited number of studies on $k_{L} a$ have been conducted in laboratory-scale stirred tanks with a working volume $(V)$ of less than $10 \mathrm{~L}$ (Arjunwadkar et al. 1998; Linek, Kordač, and Moucha 2005; Puthli, Rathod, and Pandit 2005) (Table 1). Linek, Kordač, and Moucha (2005) used the steady-state method to measure $k_{L} a$ in a $6 \mathrm{~L}$ nonstandard stirred tank $\left(H_{L / T}=1.2\right)$. Aqueous solutions of carboxymethylcellulose sodium salt (CMC) with different concentrations were used as non-Newtonian fluids. The rheological data of the non-Newtonian fluids are not reported. The physical properties (i.e., density, viscosity,

Table 1: Overview of experimental research on $k_{L} a$ in non-standard stirred tanks with non-Newtonian fluids. RT, Rushton turbine with flat blades; PBT, pitched blade turbine; LDB, large-double-blade; FZ, Fullzone; MB, Maxblend; SC, Scaba; MP, marine propeller; CMC, carboxymethylcellulose sodium salt; XG, xanthan gum.

\begin{tabular}{|c|c|c|c|c|c|c|c|}
\hline Author & $V(\mathrm{~L})$ & $H_{L / T}{ }^{(-)}$ & $N_{s}\left(\operatorname{rev} \min ^{-1}\right)$ & $Q\left(\mathrm{~L} \min ^{-1}\right)$ & Impeller number and type & $\begin{array}{l}\text { Non-Newtonian } \\
\text { polymer type and } \\
\text { wt\% }\end{array}$ & $\begin{array}{l}k_{L} a \\
\text { method }\end{array}$ \\
\hline $\begin{array}{l}\text { Linek, Kordač, and Moucha } \\
\text { (2005) }\end{array}$ & 6.0 & 1.2 & $330-1130$ & $3-9$ & Single: RT & CMC: $0.2-0.6 \%$ & $\begin{array}{l}\text { Steady- } \\
\text { state }\end{array}$ \\
\hline Arjunwadkar et al. (1998) & 5.0 & 1.2 & $400-750$ & $1.5-5.0$ & Double: RT + PBT & CMC: $0.7 \%$ & Dynamic \\
\hline $\begin{array}{l}\text { Puthli, Rathod, and Pandit } \\
\text { (2005) }\end{array}$ & 2.0 & 1.7 & $300-600$ & $0.5-2.0$ & $\begin{array}{l}\text { Single: } R T \\
\text { Double: } R T+P B T \\
\text { Triple: } R T+P B T+P B T\end{array}$ & CMC: $0.25-0.5 \%$ & Dynamic \\
\hline Liu et al. (2019) & 56 & 1.4 & $60-150$ & $17-33$ & Single: LDB, FZ, MB & $X G: 0.5 \%$ & Dynamic \\
\hline Liu et al. (2020) & 56 & 1.4 & $60-150$ & $0-50$ & Single: LDB, FZ, MB & $X G: 0.25-1.0 \%$ & Dynamic \\
\hline $\begin{array}{l}\text { Jamshidzadeh, Ein- } \\
\text { Mozaffari, and Lohi (2020) }\end{array}$ & 62 & 1.25 & $100-450$ & $6.0-12.5$ & Triple: SC + PBT + Anchor & CMC: $0.5-1.5 \%$ & Dynamic \\
\hline Gabelle et al. (2011) & $\begin{array}{r}21-42 \\
170-340\end{array}$ & 1,2 & $100-1000$ & $8-330$ & $\begin{array}{l}\text { Single: } R T, P B T, M P \\
\text { Double: } R T+P B T, R T+M P \text {, } \\
\text { RT + RT, } M P+M P\end{array}$ & $\begin{array}{l}\text { CMC, XG: } 0.25 \\
0.5 \%\end{array}$ & Dynamic \\
\hline This work & $\begin{array}{r}11,47 \\
40\end{array}$ & $1,3.5$ & $800-1000$ & $8-10$ & $\begin{array}{l}\text { Single: RT } \\
\text { Quadruple: RT }\end{array}$ & CMC: $0.2-0.6 \%$ & Dynamic \\
\hline
\end{tabular}


and molecular weight) of CMC polymer used to prepare non-Newtonian fluids are also not provided, thus preventing the identification of the polymer type (Nishikawa et al. 1981). Polymers for preparing non-Newtonian fluids are generally graded on different viscosities (or molecular weights). A small change in polymer concentration can drastically influence the rheological behavior of nonNewtonian fluids. Therefore, providing the physical properties of the polymer enables us to compare the reported results with those of future work. Puthli, Rathod, and Pandit (2005) and Arjunwadkar et al. (1998) conducted experiments in a $2 \mathrm{~L}\left(H_{L / T}=1.7\right)$ and $5 \mathrm{~L}\left(H_{L / T}=1.2\right)$ nonstandard stirred tank, respectively. $k_{L} a$ was measured in aqueous CMC solutions of different concentrations by using the dynamic method. However, the rheological data of non-Newtonian fluids and physical properties of CMC polymer are not provided (Arjunwadkar et al. 1998; Puthli, Rathod, and Pandit 2005).

Very few studies have also focused pilot-scale stirred tanks with working volumes ranging from 56 to $340 \mathrm{~L}$ (Table 1). Liu et al. $(2019,2020)$ measured $k_{L} a$ in a $56 \mathrm{~L}$ nonstandard stirred tank $\left(H_{L / T}=1.4\right)$. The dynamic method is used to measure $k_{L} a$ in aqueous xanthan gum (XG) solutions of different concentrations. The flow behavior of $X G$ is described by the power-law model. Similarly, Jamshidzadeh, Ein-Mozaffari, and Lohi (2020) conducted experiments on a $62 \mathrm{~L}$ stirred tank with a $H_{L / T}$ of 1.25 . The shear-thinning behavior of CMC solutions with different concentrations is described by the power-law model. However, the physical properties of XG and CMC polymers are not reported by Liu et al. $(2019,2020)$ and Jamshidzadeh, Ein-Mozaffari, and Lohi (2020), respectively. Furthermore, Gabelle et al. (2011) studied the effects of tank size on $k_{L} a$ by using two stirred tanks with standard $\left(H_{L / T}=1\right)$ and non-standard $\left(H_{L} / T=2\right)$ geometries. $k_{L} a$ of aqueous CMC and XG solutions is obtained using a dynamic method. The maximum and minimum working volumes of the tanks are 42 and $340 \mathrm{~L}$, respectively. The rheological behavior of shear-thinning fluids is expressed by the power-law model. The physical properties of CMC and XG polymers are also provided (Gabelle et al. 2011).

Studies focusing on the effects of geometric parameters on $k_{L} a$ with non-Newtonian fluids are few (Table 1), particularly those using non-standard pilot-scale stirred tanks limited to $H_{L / T}$ of 1-2. Therefore, in view of the bioprocess industry, the effect of geometric parameters on $k_{L} a$ of non-Newtonian fluids must be investigated using pilotscale stirred tanks with $H_{L / T}$ higher than 2 . The results can help determine the behavior of $k_{L} a$ during scale-up, as well as the optimal tank size and $H_{L / T}$. To fill this research gap, the present study aimed to investigate the effects of geometric parameters (tank size and $H_{L / T}$ ) on $k_{L} a$ of shearthinning fluids by operating standard and non-standard stirred tanks. Three stirred tanks with different sizes (laboratory and pilot-scale) and geometry (standard and non-standard) were used. The values of $H_{L / T}$ were 1 for standard and 3.5 for nonstandard stirred tanks. The volumes of the stirred tanks were $11 \mathrm{~L}\left(H_{L / T}=1\right), 40 \mathrm{~L}$ $\left(H_{L} / T=3.5\right)$, and $47 \mathrm{~L}\left(H_{L / T}=1\right) . k_{L} a$ was estimated using a dynamic method based on recorded DO concentrations in liquids. Additionally, $k_{L} a$ was evaluated with the effects of fluid rheology and operating conditions. The effects of different types of polymers (for preparing shear-thinning fluids) on $k_{L} a$ were examined. The obtained results of $k_{L} a$ were compared with existing experimental data in literature and those obtained by empirical correlation.

\section{Materials and methods}

\subsection{Experimental setup}

The experiments were conducted in three flat-bottomed stirred tanks made of plexiglass with different geometrical configurations (Figure 1). Tank A was a laboratory-scale model with a standard geometry $\left(H_{L} / T=1\right)$, and working volume of $11 \mathrm{~L}$. Tank B was a pilot-scale model, which was scaled up from Tank A. Tank B had a standard geometry $\left(H_{L / T}=1\right)$ with a working volume of $47 \mathrm{~L}$. Tank $\mathrm{C}$ was also a pilot-scale model, but with nonstandard geometry $\left(H_{L / T}=3.5\right)$ and a working volume of $40 \mathrm{~L}$. The detailed geometric configurations of the stirred tanks are presented in Table 2. Recirculation zones were reduced by equipping the stirred tanks with four equispaced $\left(90^{\circ}\right.$ apart) rectangular baffles. Mixing in the tanks was achieved with a six-blade Rushton turbine mounted to IKA EUROSTAR 200 control (Tank A) and IKA RW 47 digital (Tank B and Tank C) overhead stirrers. Tank A and Tank B both have one impeller, whereas Tank $C$ had four, as shown in Figure 1(c). The gas was introduced to Tank A and Tank $\mathrm{C}$ with a ring sparger. By contrast, a C-type ring sparger was used in Tank B. Impeller speeds and sparger gas flow rates ranged from $800 \mathrm{rev} \mathrm{min}^{-1}$ to $900 \mathrm{rev} \mathrm{min}^{-1}$ and from $8 \mathrm{~L} \mathrm{~min}^{-1}$ to $10 \mathrm{~L} \mathrm{~min}^{-1}$, respectively. The selected operating conditions facilitated the supply of gas from each sparger hole and the dispersion of the gas bubbles across the entire tank. The bubbly flow regime was observed within the range at which experiments were conducted (Figure 1). The measurement positions (location of $\mathrm{O}_{2}$ probe) of DO concentrations inside the stirred tanks are shown in Figure 1. All the experiments were repeated three times for each selected impeller speed and gas flow rate. The repeatability of the presented results was checked through statistical analysis. Standard error bars were plotted for all the experimental results, but the error bars may not be visible for a specific result because of the low standard errors for the repeatability of measurements. The experiments were conducted at room temperature conditions $\left(22^{\circ} \mathrm{C} \pm 1{ }^{\circ} \mathrm{C}\right)$. 
Tank A

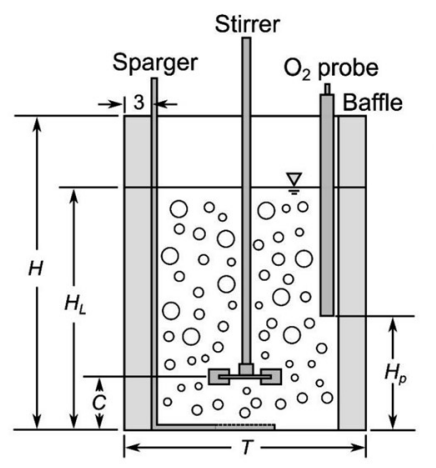

(a)
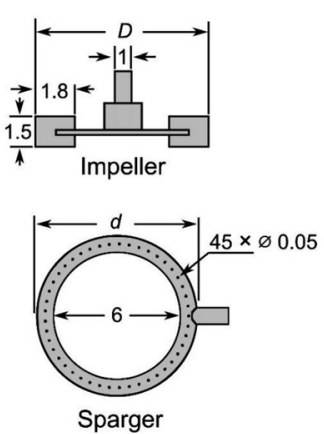

$\underline{\text { Tank B }}$
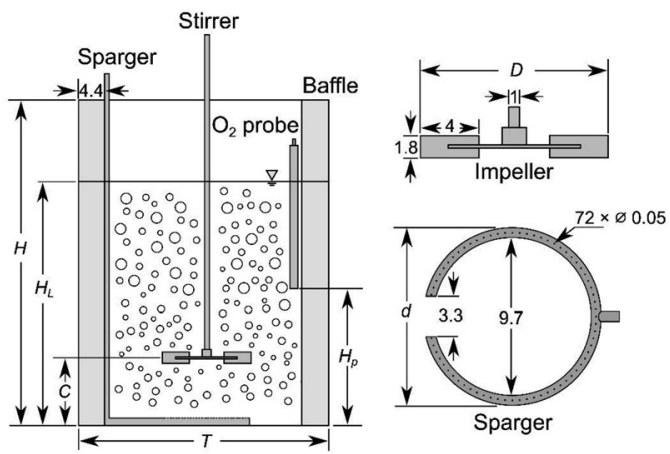

(b)

$\underline{\text { Tank C }}$

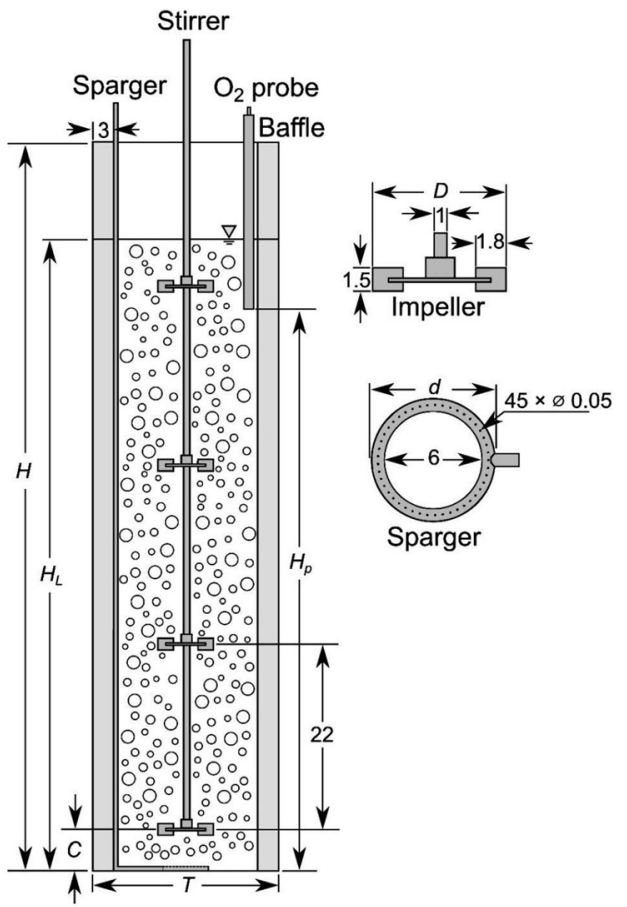

(c)

Figure 1: Schematic diagram of the stirred tanks with working volumes of (a) 11, (b) 47, and (c) $40 \mathrm{~L}$. All dimensions are in the units of centimeter.

Table 2: Detailed geometric configurations of the stirred tanks.

\begin{tabular}{|c|c|c|c|c|c|c|c|c|c|}
\hline Geometry & Volume (L) & $H_{L / T}{ }^{(-)}$ & $T(\mathrm{~cm})$ & $H(\mathrm{~cm})$ & $H_{L}(\mathrm{~cm})$ & $C(\mathrm{~cm})$ & $H_{p}(\mathrm{~cm})$ & $D(\mathrm{~cm})$ & $d(\mathrm{~cm})$ \\
\hline Tank A & 11 & 1 & 24 & 32.5 & 24 & 5.5 & 8.2 & 7.3 & 6.5 \\
\hline Tank B & 47 & 1 & 40 & 53 & 40 & 11 & 22 & 11.3 & 11.3 \\
\hline Tank C & 40 & 3.5 & 25 & 100 & 88 & 5.5 & 75.5 & 7.3 & 6.5 \\
\hline
\end{tabular}




\subsection{Measurements}

2.2.1 Rheology: The tested fluids were deionized water and nonNewtonian solution made of CMC. Four types of CMC polymers (SigmaAldrich, Norway) based on different polymer viscosities were used in preparing non-Newtonian fluids: low (viscosity $=0.05-0.2 \mathrm{~Pa} \mathrm{~s}$ ), medium (viscosity $=0.4-1.0 \mathrm{~Pa} \mathrm{~s}$ ), high (viscosity $=1.5-3.0 \mathrm{~Pa} \mathrm{~s}$ ), and ultra-high (viscosity $=1.5-4.5 \mathrm{~Pa} \mathrm{~s}$ ). Differences in the viscosities of the CMC polymers influenced the apparent viscosities and transparency of the non-Newtonian fluids. Low, medium, and high-viscous CMCs are suspending agents, i.e., the particles stay suspended in the non-Newtonian solutions that makes them opaque. However, ultrahigh-viscous CMC is highly purified and less suspended; thus, the non-Newtonian solutions made from ultra-high-viscous CMC are transparent. Moreover, four mass concentrations (wt\%) of CMC were used in examining shear-thinning behavior on mass transfer rate: $0.2 \%, 0.3 \%, 0.4 \%$, and $0.6 \%$. The non-Newtonian fluid samples of

Low-viscous CMC

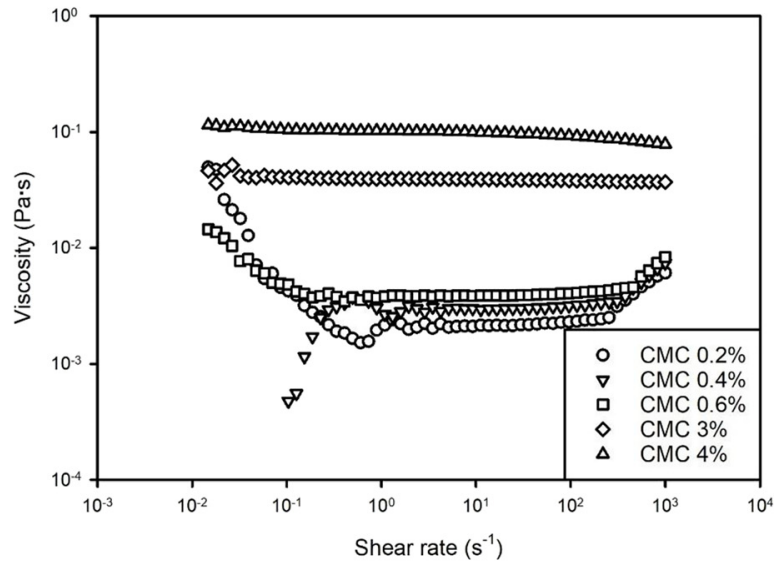

(a)

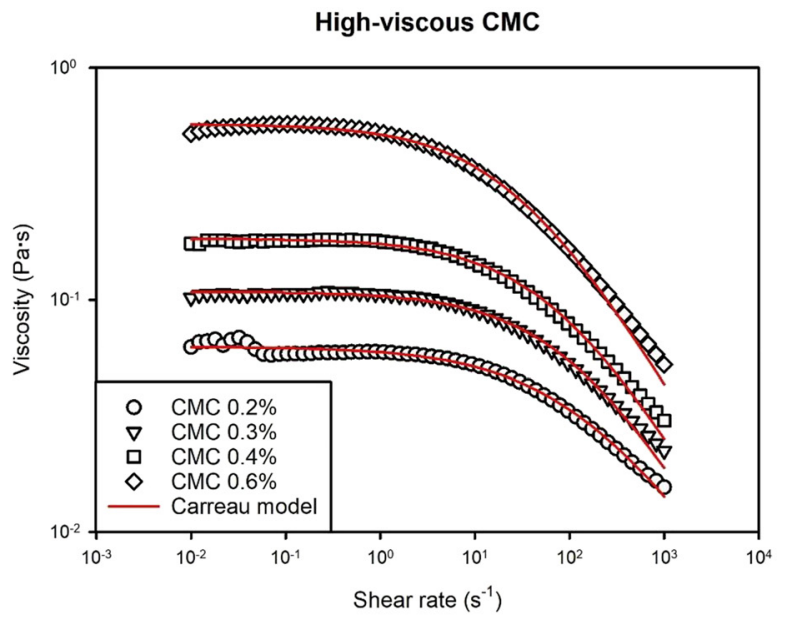

(c)
CMC were prepared with deionized water. The apparent viscosities of the samples were measured using a rheometer (Physcia MCR 301, Anton Paar GmbH, Austria) with a concentric cylindrical geometry. The samples were given a rest time of $10 \mathrm{~min}$ before each measurement for them to reach thermal equilibrium (temperature $=22^{\circ} \mathrm{C}$ ) and for the removal of the smallest trapped bubbles in the fluids. Each rheology measurement was repeated twice. The Metzner-Otto correlation was used in relating average shear rate in the stirred tank to stirring speed:

$$
\dot{\gamma}=k_{s} N_{s}
$$

where $\dot{y}$ is the applied shear rate $\left(\mathrm{s}^{-1}\right), k_{s}$ is the Metzner constant (-), and $N_{s}$ is the stirring speed $\left(\mathrm{s}^{-1}\right)$. The $k_{s}$ values for six-blade Rushton turbine were assumed 11.5 (Metzner and Otto 1957). Given this $k_{s}$ value, a shear rate in the range of $0.001-1000 \mathrm{~s}^{-1}$ was used in investigating the shear-thinning behaviors of the non-Newtonian samples. Rheological data (shear stress and apparent viscosity) for the CMC solutions

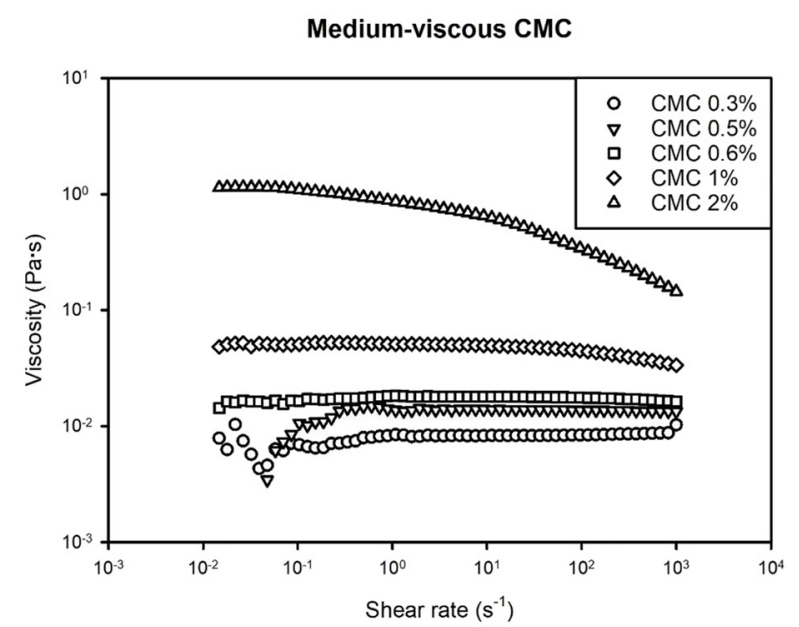

(b)

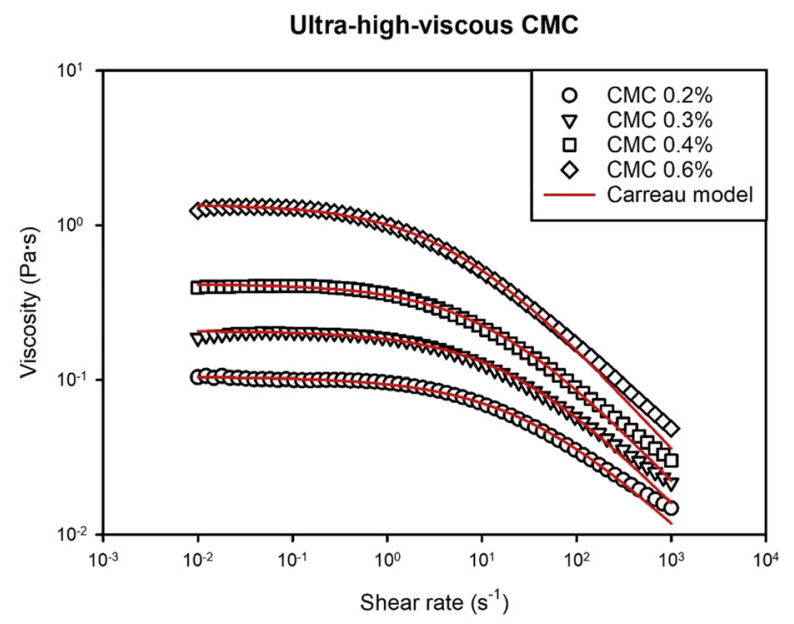

(d)

Figure 2: Apparent viscosity of $\mathrm{CMC}$ with the effects of shear rates. Apparent viscosity and shear rates are presented on a logarithmic scale. 
are plotted in Figure 2. Non-Newtonian solutions made from highviscous and ultra-high-viscous CMC polymers showed shear-thinning behavior, as shown in Figures 2(c) and 2(d). A noise from the rheometer was recorded for the liquids whose apparent viscosities are comparable to water [Figure 2(a) and (b)]. Thus, the solutions prepared from high-viscous and ultra-high-viscous CMC polymers were selected for the measurement of $k_{L} a$. The apparent viscosities of the CMC solutions are represented using the Carreau model:

$$
\mu_{a}=\mu_{\infty}+\left(\mu_{0}-\mu_{\infty}\right)\left[1+(\lambda \dot{y})^{2}\right]^{\frac{n-1}{2}}
$$

where $\mu_{a}$ represents apparent fluid viscosity (Pa s), $\mu_{0}$ and $\mu_{\infty}$ are fluid viscosities at minimum and maximum shear rates ( $\mathrm{Pa} \mathrm{s}), \lambda$ is the time at which the behavior of a fluid changes from Newtonian to power-law (s), and $n$ is the power-law index (-). The physical properties of the experimental fluids are presented in Table 3. Reynolds number based on impeller diameter was in the range of 400-75,000 for Tanks A and C, whereas 1000-182,000 for Tank B.

2.2.2 Volumetric mass transfer coefficient: The $k_{L} a$ values in the stirred tanks were predicted using a dynamic gassing-in method (Garcia-Ochoa and Gomez 2009). Each tank was first deoxygenated with sparging nitrogen gas until DO concentration was less than $2 \%$. Cleaned compressed air was then supplied until DO concentration reached $98 \%$. The opening and closing of the nitrogen and air valves were controlled with the LabVIEW software. DO concentration was recorded every $5 \mathrm{~s}$ with an optical $\mathrm{O}_{2}$ probe $\left(\mathrm{InPro}^{\circledR}\right.$ 6870i, Mettler Toledo, Switzerland). Recorded data were monitored and saved using a multiparameter transmitter (M800, Mettler Toledo, Switzerland). The positioning of the $\mathrm{O}_{2}$ probe inside each stirred tank is illustrated in Figure 1. The $\mathrm{O}_{2}$ probe was calibrated with a two-point calibration method before each experiment. Two-point calibration involved calibration in air (DO concentration $=100 \%$ ) followed by calibration in nitrogen (DO concentration $=0 \%$ ). This calibration procedure provided the most accurate calibration curve over the entire measuring range. $\tau_{p}$ of the $\mathrm{O}_{2}$ probe was significantly less than $1 / k_{L} a$. Therefore, the effects of the $\mathrm{O}_{2}$ probe were neglected in this work (de Jesus, Moreira Neto, and Maciel Filho 2017; Michelin et al. 2013). For small $k_{L} a$ values, such as those in this work, the dynamic gassing-in method can be employed provided that $\mathrm{O}_{2}$ only is considered during air absorption (Linek et al. 1982; Scargiali et al. 2007, 2010). Thus, the rate of change in oxygen concentration in a liquid can be described using

Table 3: Physical properties of the experimental fluids used in the study.

\begin{tabular}{llrrr}
\hline Fluid & CMC polymer & $\boldsymbol{\mu}_{\boldsymbol{a}} \times \mathbf{1 0}^{-\mathbf{3}}$ (Pa-s) & \multicolumn{2}{c}{ Carreau model } \\
\cline { 4 - 5 } & & & $\boldsymbol{n}(-)$ & $\boldsymbol{\lambda}(\mathbf{s})$ \\
\hline Water & - & 1.00 & - & - \\
CMC 0.2\% & High-viscous & - & 0.7409 & 0.1217 \\
CMC 0.3\% & High-viscous & - & 0.6972 & 0.1051 \\
CMC 0.4\% & High-viscous & - & 0.6929 & 0.1717 \\
CMC 0.6\% & High-viscous & - & 0.6693 & 0.3904 \\
CMC 0.2\% & Ultra-high-viscous & - & 0.6892 & 0.2815 \\
CMC 0.3\% & Ultra-high-viscous & - & 0.6713 & 0.4255 \\
CMC 0.4\% & Ultra-high-viscous & - & 0.6547 & 0.6749 \\
CMC 0.6\% & Ultra-high-viscous & - & 0.6211 & 1.4695 \\
\hline
\end{tabular}

the following equation (Badino, Facciotti, and Schmidell 2001; Nauha et al. 2015):

$$
\frac{d C_{t}}{d t}=k_{L} a\left(\bar{C}-C_{t}\right)
$$

where $C_{t}$ is the measured local DO concentration in a liquid (mol L ${ }^{-1}$ ) and $\bar{C}$ is the saturation concentration of oxygen $\left(\mathrm{mol} \mathrm{L}^{-1}\right)$. Henry's law was used in determining $\bar{C}$.

$$
\bar{C}=K_{\mathrm{H}} P_{\mathrm{O}_{2}} \text { with } P_{\mathrm{O}_{2}}=X_{\mathrm{O}_{2}}\left(P_{\text {air }}-P_{\mathrm{H}_{2} \mathrm{O}}\right)
$$

where $K_{H}$ represents Henry's Law constant (mol L-1 atm), $P_{\mathrm{O}_{2}}$ is the partial pressure of oxygen (atm), $X_{\mathrm{O}_{2}}$ is oxygen molar fraction (\%), $P_{\text {air }}$ is the partial pressure of air (atm), and $P_{\mathrm{H}_{2} \mathrm{O}}$ is the partial pressure of water vapors for $100 \%$ relative humidity (atm). The value of $\bar{C}$ varied for each experiment depending on the fluid rheology and operating conditions. The variation in $X_{\mathrm{O}_{2}}$ was negligible with liquid height (Ali and Solsvik 2020). Equation (3) was integrated as a linear equation.

$$
\ln \left(\frac{\bar{C}-C_{t}}{\bar{C}-C_{t=0}}\right)=-k_{L} a \times t
$$

where $t$ is the time (s), $C_{t=0}$ is the DO concentration that is less than $5 \%$ at $t=0 \mathrm{~s}\left(\mathrm{~mol} \mathrm{~L}^{-1}\right)$, and $k_{L} a$ is estimated by plotting $\ln \left(\frac{\bar{C}-C_{t}}{\bar{C}-C_{t=0}}\right)$ against $t$ with a linear regression. MATLAB (R2019b, MathWorks, USA) was used (de Jesus, Moreira Neto, and Maciel Filho 2017; Michelin et al. 2013).

2.2.3 Power input: The power input of each stirred tank was estimated using the correlation proposed by Prasher and Wills (1973)

$$
\begin{gathered}
\frac{P_{\mathrm{g}}}{V}=\frac{P_{o} N_{s}^{3} D^{5} \rho \varphi}{T^{2} H} \\
\varphi=1.0-1.26 \frac{Q}{N_{s} D^{3}} \quad \text { for } \frac{Q}{N_{s} D^{3}}<3.5 \times 10^{-2} \\
\varphi=0.62-1.85 \frac{Q}{N_{s} D^{3}} \quad \text { for } \frac{Q}{N_{s} D^{3}}>3.5 \times 10^{-2}
\end{gathered}
$$

where $P_{g} / V$ is the power input per unit liquid volume $\left(\mathrm{W} \mathrm{m}^{-3}\right), P_{o}$ is the power number (-), $N_{s}$ is the impeller speed $\left(\mathrm{s}^{-1}\right), D$ is the diameter of a stirrer $(\mathrm{m}), T$ is tank inner diameter $(\mathrm{m}), H$ is liquid height $(\mathrm{m})$, and $Q$ is gas flow rate $\left(\mathrm{m}^{3} \mathrm{~s}^{-1}\right) . P_{o}$ of the Rushton turbine stirrer was estimated from the characteristic curve of the Power number-Reynolds number for each experimental fluid (Bates, Fondy, and Corpstein 1963). Taghavi et al. (2011) and Devi and Kumar (2017) showed that the correlation (Eq. 6) can be used in estimating the total power input of aerated stirred tanks with different scales (Devi and Kumar 2017; Taghavi et al. 2011).

\section{Results and discussion}

\subsection{Rheology}

The effects of different types of fluids and CMC polymers on the volumetric mass transfer coefficient $\left(k_{L} a\right)$ are plotted in Figure 3. The bubbles produced in water were large 
compared to that of CMC, whereas the bubble count was significantly higher in CMC than in water (Ali and Solsvik 2020, 2021). However, the higher viscosity of CMC solutions decreased the fluid mixing (turbulence), which consequently reduced the rate of bubbles dissolution (DO concentration) in the liquid. Thus, the $k_{L} a$ value in water was approximately two and three times greater than the values in high-viscous CMC 0.3\% and ultra-high-viscous

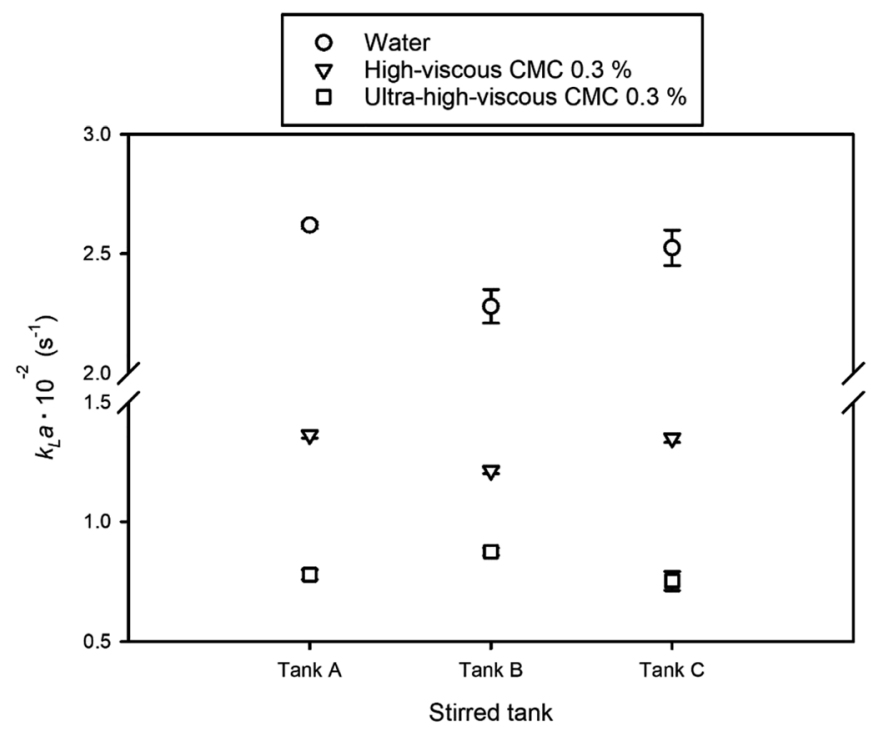

(a)

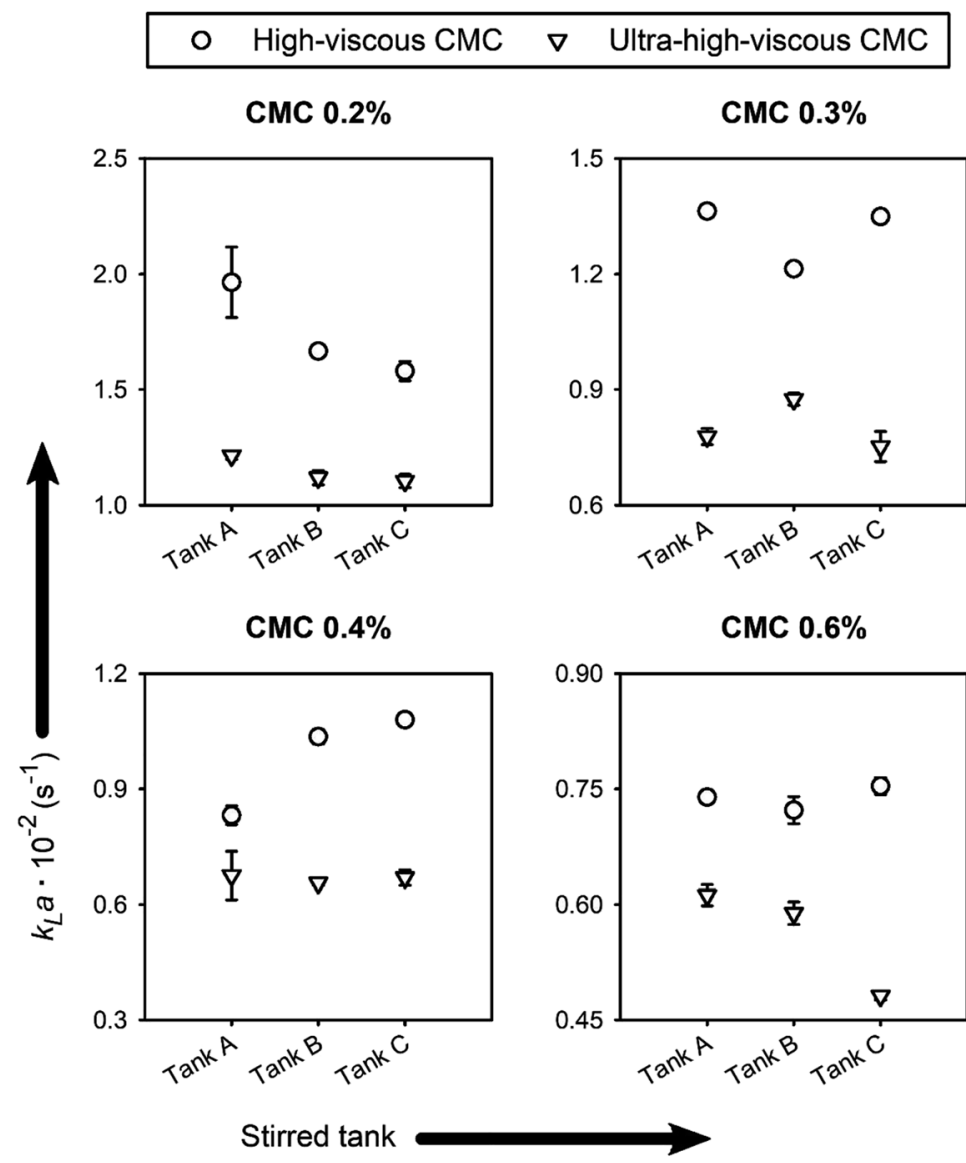

(b)
Figure 3: $k_{L} a$ with effects of different (a) fluid and (b) CMC types at impeller speed and gas flow rate of 800 (rev $\left.\mathrm{min}^{-1}\right)$ and $8\left(\mathrm{~L} \mathrm{~min}^{-1}\right)$, respectively. 
CMC 0.3\%, respectively (Figure 3a). Under the same operating conditions, the decrease in $k_{L} a$ in the scaled-up tanks (Tanks B and C) was attributed to high bubble coalescence caused by low stirrer-induced turbulence (large eddies). Large bubbles cannot dissolve easily in liquids, thereby reducing DO concentration and $k_{L} a$. However, the higher number of impellers in Tank $\mathrm{C}$ prompted bubble breakage by increasing the production of small-scale eddies, thereby improving $k_{L} a$. The $k_{L} a$ of water in Tank A was 13 and $1 \%$ higher than the values in Tank B and Tank C, respectively. The $k_{L} a$ value in Tank $\mathrm{C}$ was $9.8 \%$ higher than that in Tank B. Similarly, the $k_{L} a$ of the high-viscous CMC $0.3 \%$ in Tank A was 11 and 3.7\% higher than the values in Tanks B and C, respectively, and the value in Tank $\mathrm{C}$ was $10 \%$ higher than that in Tank B. However, the $k_{L} a$ of ultra-high-viscous CMC $0.3 \%$ in Tank A was 11\% lower and 3.3\% higher than the values in Tanks B and C, respectively. The $k_{L} a$ value in Tank C was 14\% lower than that in Tank B. The type and
Water

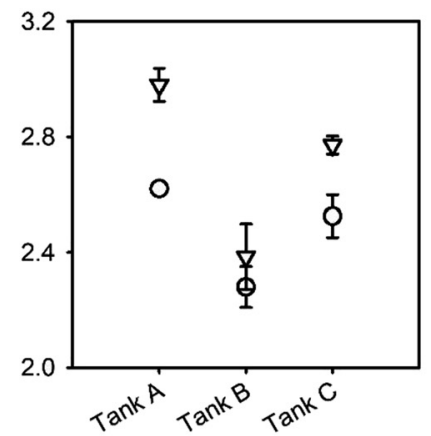

CMC $\mathbf{0 . 4 \%}$

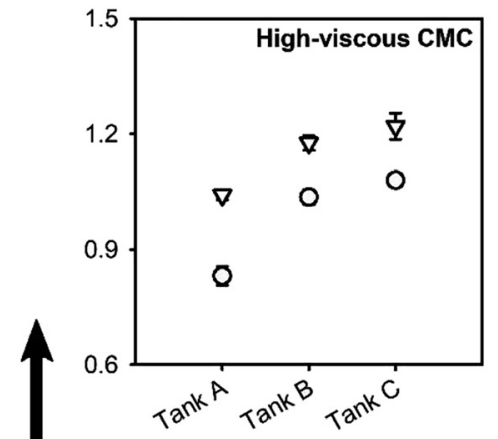

CMC $0.3 \%$

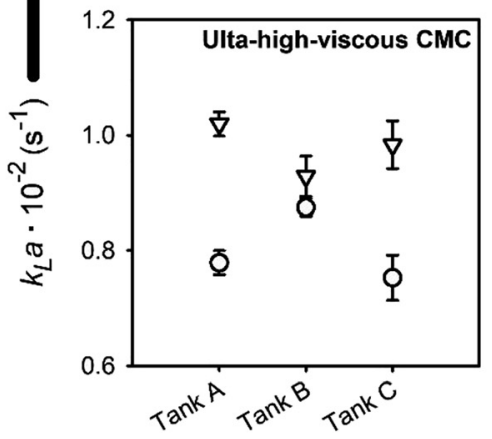

CMC $0.2 \%$

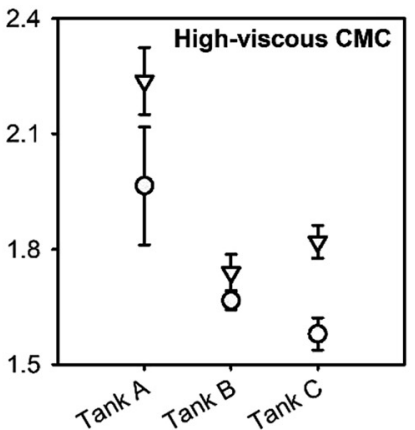

CMC $0.6 \%$

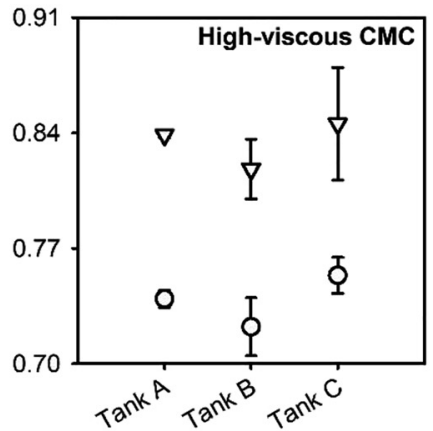

CMC $0.4 \%$

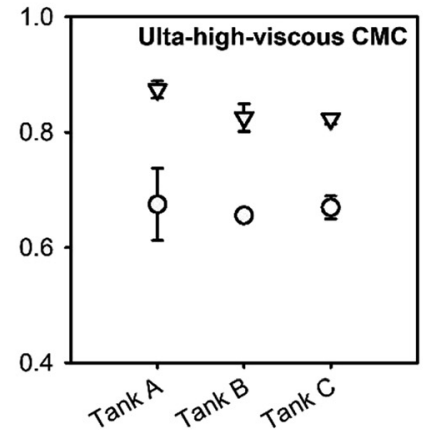

CMC $0.3 \%$

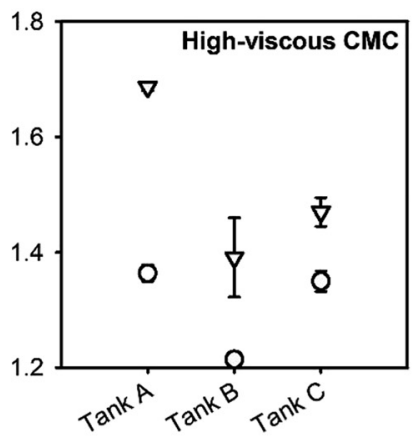

CMC $0.2 \%$

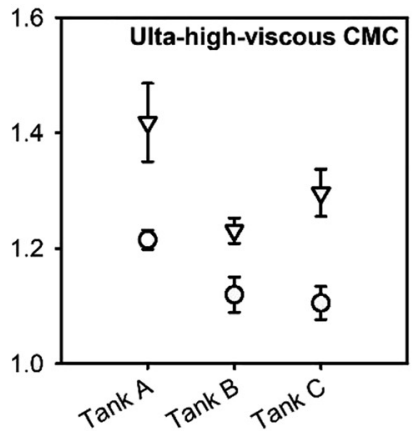

CMC $0.6 \%$

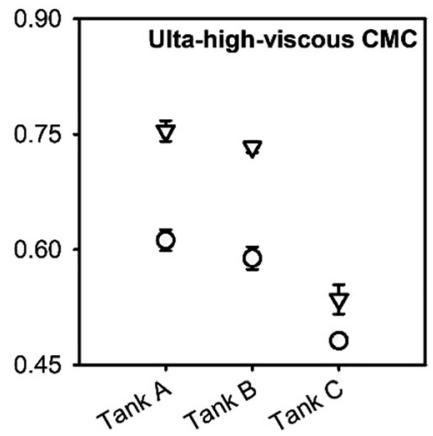

Stirred tank

Figure 4: $k_{L} a$ with effects of different impeller speeds at a gas flow rate of $8 \mathrm{~L} \mathrm{~min}^{-1}$. 
concentration of CMC polymer negatively affected $k_{L} a$, as shown in Figure $3 \mathrm{~b}$. The $k_{L} a$ values in high-viscous CMC solutions were two times higher than the values in ultrahigh-viscous CMC. In addition, $k_{L} a$ decreased as CMC polymer concentration increased. An increase in CMC concentration (in both types of CMC polymers) from $0.2 \%$ to $0.3 \%$ significantly impacted $k_{L} a$. However, $k_{L} a$ was only marginally impacted by an increase in CMC concentration from $0.4 \%$ to $0.6 \%$, especially in ultra-high-viscous CMC. This suggests that the system reached a limit, and that additional increases in CMC concentration did not have significant effects on $k_{L} a$ due to the reduced driving force. The $k_{L} a$ values showed somewhat similar trends; the highest values were found in Tank A and the lowest in Tank C. However, from a physical point of view, the deviation of $k_{L} a$ from the general trend was due to experimental error.

\subsection{Operating conditions}

The effects of impeller speed $\left(N_{\mathrm{S}}\right)$ on $k_{\mathrm{L}} a$ in different CMC polymers and concentrations are presented in Figure 4. With a fixed $Q$ of $8 \mathrm{~L} \mathrm{~min}^{-1}$, an increase in $N_{\mathrm{s}}$ enhanced the turbulence which in return promoted the bubble breakage. The size of the bubbles decreased, thereby increasing their dissolution into the liquid. Thus, increasing the magnitude of $N_{\mathrm{s}}$ improved DO concentration and subsequently increased $k_{L} a$. The effect of increasing $N_{\mathrm{S}}$ on $k_{L} a$ was considerably stronger in water; this effect was least pronounced in the ultra-high-viscous CMC. An increase in $N_{\mathrm{s}}$ at low CMC concentrations ( 0.2 and $0.3 \%$ ) yielded significant differences in $k_{L} a$. However, at high CMC concentrations ( 0.4 and $0.6 \%$ ), especially in ultra-high-viscous CMC, the impact of $N_{\mathrm{S}}$ on $k_{L} a$ was small due to substantial increase in liquid viscosity. The $k_{L} a$ values were plotted as a function of $Q$ for different CMC polymers and concentrations (Figure 5). The measurement of bubble size was out of the scope of the present study and thus was not performed. The understanding of the relation of $k_{L} a$ with bubble size was inferred from our previous work (Ali and Solsvik 2020). $N_{\mathrm{s}}$ was maintained constant at $800 \mathrm{rev} \mathrm{min}^{-1}$, thereby increasing $Q$ supported bubble coalescence, and accordingly, the bubble size increased (Ali and Solsvik 2020). Large bubbles are difficult to dissolve in the liquid, thus improving DO concentrations marginally. Moreover, an increase in $Q$ also increased the size of gas cavities behind the impeller blades (Cappello et al. 2020). These effects explain the slight increase in the magnitude of $k_{L} a$ by increasing $Q$. Increasing $Q$ had a more pronounced effect on $k_{L} a$ in water; this effect was much smaller in viscous fluids. The effect of $Q$ on $k_{L} a$ was considerable at low CMC concentrations (0.2 and $0.3 \%$ ) and nominal at high CMC concentrations (0.4 and 0.6\%). These findings imply that the impacts of operating conditions $\left(N_{\mathrm{s}}\right.$ and $\left.Q\right)$ on $k_{L} a$ depend on rheology (liquid viscosity). Therefore, increasing the operating conditions in high CMC concentrations will not significantly improve $k_{L} a$.

\subsection{Experimental comparison}

$k_{L} a$ measured in the present study was compared with the results of our laboratory-scale $(V=11 \mathrm{~L})$ (Ali and Solsvik 2020) and pilot-scale ( $V=50 \mathrm{~L}$ ) (Ali and Solsvik 2021) standard geometry stirred tanks and with results for standard and non-standard geometry stirred tanks found in the literature (Figure 6). Student's $t$-test (SigmaPlot, 14.0, Systat Software Inc., USA) was used to evaluate the standardized mean difference (SMD) between the results. The comparison with $k_{L} a$ presented in Figure 6(a) uses experimental data obtained in the standard stirred tanks. For Newtonian fluids, the values of $k_{L} a$ reported in this work were close to those of our laboratory-scale stirred tank (Ali and Solsvik 2020) (SMD = 2\%). The SMD between the values of $k_{L} a$ obtained in this work and those from our pilot-scale stirred tank was approximately 3.1\% (Ali and Solsvik 2021). The deviation between the results was due to differences in impeller bottom clearance $(C)$ and operating conditions.

The SMDs between the results of this work and those of Petř̌čcek et al. (2018) and Cappello et al. (2020) were approximately 10.4 and $15.4 \%$, respectively. Comparing $k_{L} a$ in non-Newtonian fluids, the SMD between the results of the present study and our laboratory-scale stirred tank was 1.1\% (Ali and Solsvik 2020). Similarly, the SMD between the $k_{L} a$ reported in this work and that of the pilotscale stirred tank was 1.3\% (Ali and Solsvik 2021), but a significant difference was observed between the results of the present study and those of Tecante and Choplin (1993) $(\mathrm{SMD}=4.72 \%)$. Comparing the values of $k_{L} a$ obtained in this work with those of Cappello et al. (2020) and GarcíaOchoa and Castro (2001) produced SMDs of 3.51 and 3.03\%, respectively.

The $k_{L} a$ results obtained in the non-standard stirred tank (Tank C) were also compared with experimental data reported in the literature, as shown in Figure 6(b). Regarding Newtonian fluids, the measured $k_{L} a$ closely matched the results of both Arjunwadkar et al. (1998) $(\mathrm{SMD}=1.1 \%)$ and Bouaifi and Roustan (1998) $(\mathrm{SMD}=1.2 \%)$. The differences between the values of $k_{L} a$ reported in the 
present study and those of Badino, Facciotti, and Schmidell (2001) and Linek et al. (2004) were 2 and 3.6\%, respectively. The SMD when comparing the results with those of Kazemzadeh et al. was high (7.1\%) (Kazemzadeh et al. 2020), but the mean difference was largest (16.3\%) between the measured $k_{L} a$ in non-Newtonian fluids and the experimental data reported by Linek, Kordač, and Moucha (2005). The results of the present study were in close agreement with Jamshidzadeh, Ein-Mozaffari, and Lohi (2020) and Liu et al. (2020), with SMDs of less than 1\%, and the mean difference between the results reported in the present work and those of Gabelle et al. (2011) was about $2.5 \%$. Different operating conditions, reactor geometry, water quality, and polymer type were among the reasons that the results of this work varied from those reported in the literature.

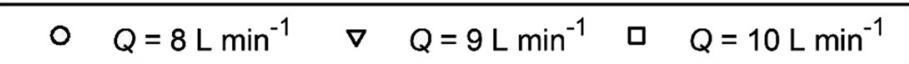

Water

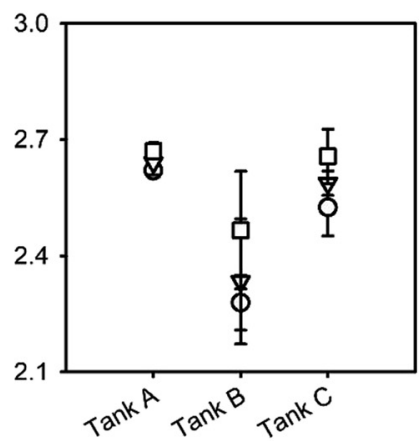

CMC $0.4 \%$

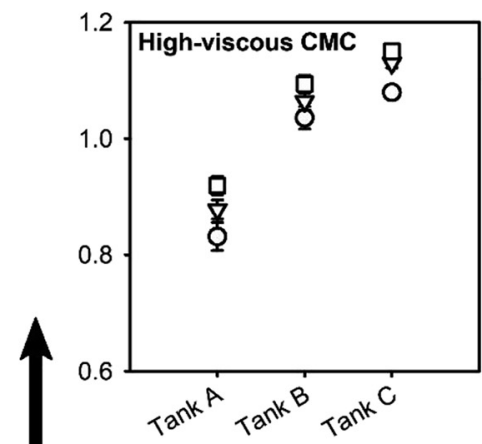

CMC $0.3 \%$

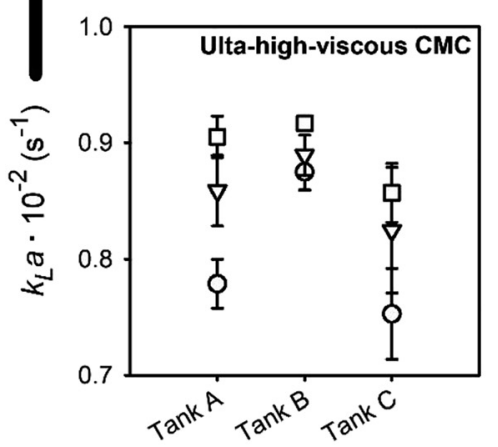

CMC $0.2 \%$

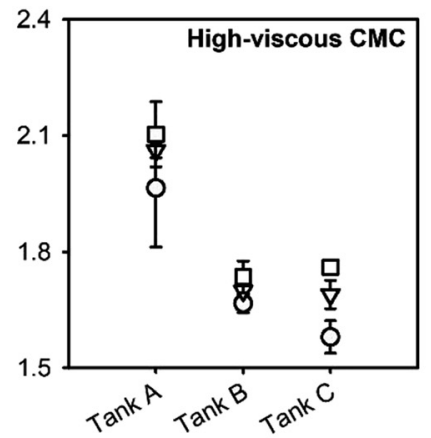

CMC $0.6 \%$

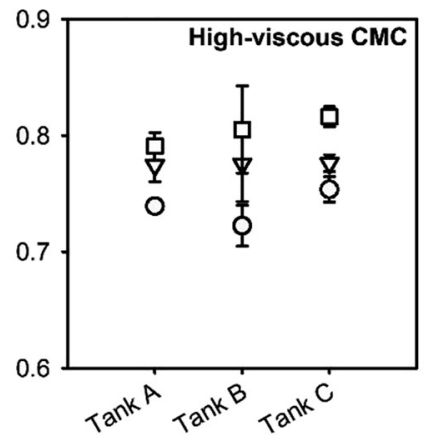

CMC $0.4 \%$

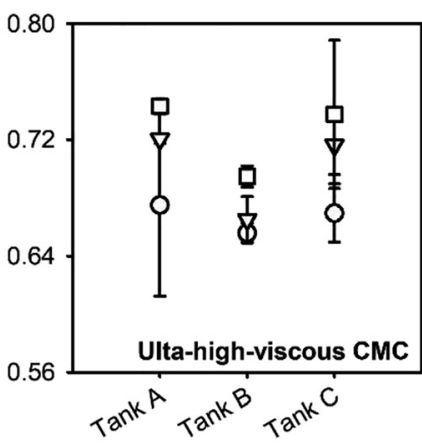

CMC $0.3 \%$

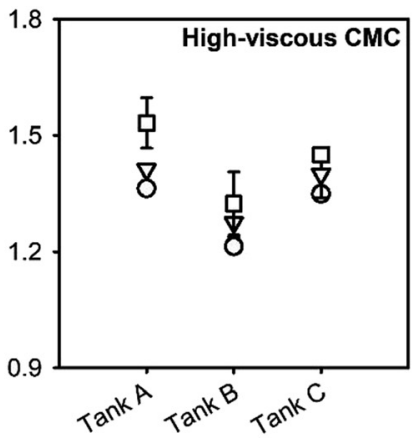

CMC $0.2 \%$

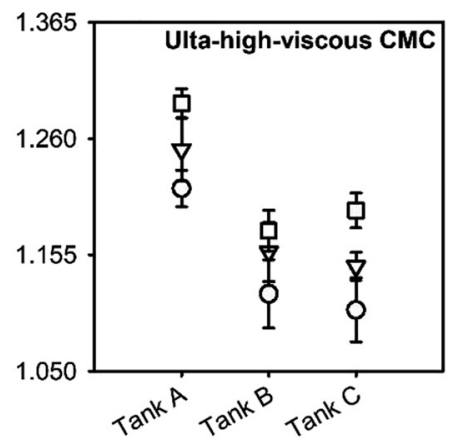

CMC $0.6 \%$

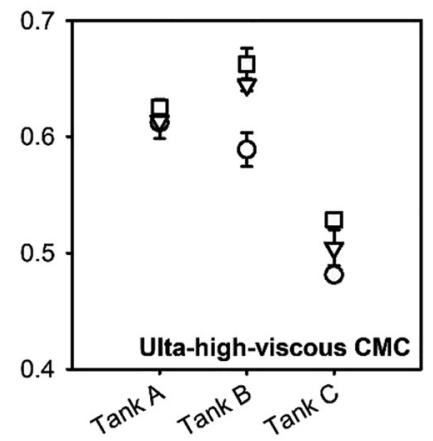

Stirred tank

Figure 5: $k_{L} a$ with effects of different sparger gas flow rates at an impeller speed of $800 \mathrm{rev} \mathrm{min}^{-1}$. 


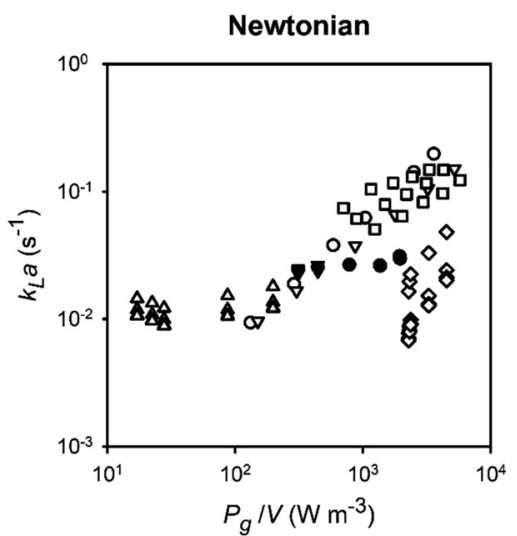

\section{Newtonian}

\begin{tabular}{|cllll|}
\hline$\circ$ & $V=18.3 \mathrm{~L}, H_{L} / T=1$ (Petřiček et al., 2018) & $\Delta$ & $V=50 \mathrm{~L}, H_{L} / T=1$ (Ali \& Solsvik, 2021) \\
$\nabla$ & $V=153 \mathrm{~L}, H_{L} / T=1$ (Petřiček et al., 2018) & $\bullet$ & $V=11 \mathrm{~L}, H_{L} / T=1$ (This work) \\
$\square$ & $V=21 \mathrm{~L}, H_{L} / T=1$ (Cappello et al., 2020) & $\nabla$ & $V=47 \mathrm{~L}, H_{L} / T=1$ (This work) \\
$\diamond$ & $V=11 \mathrm{~L}, H_{L} / T=1$ (Ali \& Solsvik, 2020) & & \\
\hline
\end{tabular}

\section{Non-Newtonian}

\begin{tabular}{lllll|}
$\circ$ & $V=8 \mathrm{~L}, H_{\mathrm{L}} / T=1$ (Tecante \& Choplin, 1993) & $\Delta$ & $V=50 \mathrm{~L}, H_{\mathrm{L}} / T=1$ (Ali \& Solsvik, 2021) \\
$\nabla$ & $V=21 \mathrm{~L}, H_{\mathrm{L}} / T=1$ (Cappello et al., 2020) & $\bullet$ & $V=11 \mathrm{~L}, H_{L} / T=1$ (This work) \\
$\square$ & $V=20 \mathrm{~L}, H_{L} / T=1$ (Garcia-Ochoa \& Castro, 2001) & $\nabla$ & $V=47 \mathrm{~L}, H_{\mathrm{L}} / T=1$ (This work) \\
$\diamond$ & $V=11 \mathrm{~L}, H_{\mathrm{L}} / T=1$ (Ali \& Solsvik, 2020) & & \\
\hline
\end{tabular}

(a)
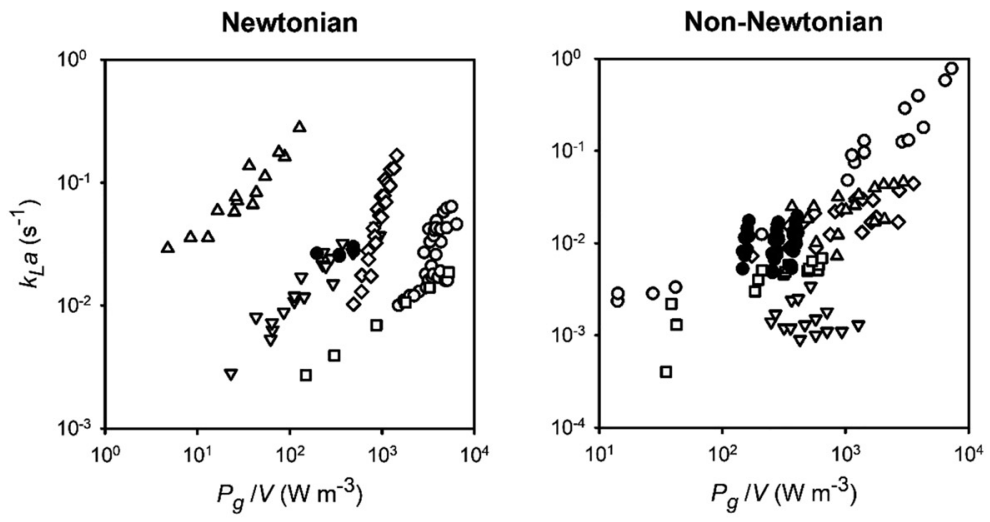

\section{Newtonian}

- $V=5 \mathrm{~L}, H_{L} / T=1.2$ (Arjunwadkar et al., 1998) $\diamond \quad V=38 \mathrm{~L}, H_{L} / T=2$ (Linek et al., 2004)

$\nabla \quad V=125 \mathrm{~L}, H_{L} / T=2$ (Bouaifi \& Roustan, 1998) $\Delta \quad V=33 \mathrm{~L}, H_{L} / T=1.43$ (Kazemzadeh et al., 2020)

व $V=10 \mathrm{~L}, H_{L} / T=1.25$ (Badino et al., 2001)

\section{Non-Newtonian}

\begin{tabular}{|cllll|}
\hline$\circ$ & $V=6 \mathrm{~L}, H_{L} / T=1.2$ (Linek et al., 2005) & $\diamond$ & $V=42 \mathrm{~L}, H_{L} / T=2$ (Gabelle et al., 2011) \\
$\nabla$ & $V=62 \mathrm{~L}, H_{L} / T=1.25$ (Jamshidzadeh et al., 2020) & $\Delta$ & $V=340 \mathrm{~L}, H_{L} / T=2$ (Gabelle et al., 2011) \\
$\square$ & $V=56.7 \mathrm{~L}, H_{L} / T=1.4$ (Liu et al., 2020) & $\bullet$ & $V=40 \mathrm{~L}, H_{L} / T=3$ (This work) \\
\hline
\end{tabular}

(b)
Figure 6: Comparison of experimentally measured $k_{L} a$ with past experimental data: (a) standard and (b) non-standard stirred tanks. $P_{\mathrm{g} / V}$ and $k_{L} a$ are presented on the logarithmic scale. 
Tank A

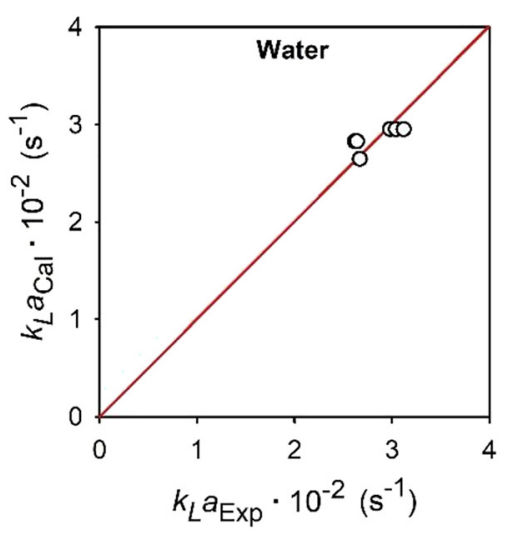

Tank A

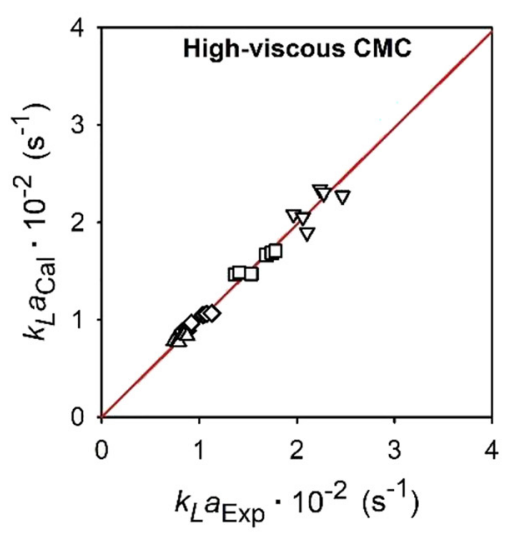

Tank A

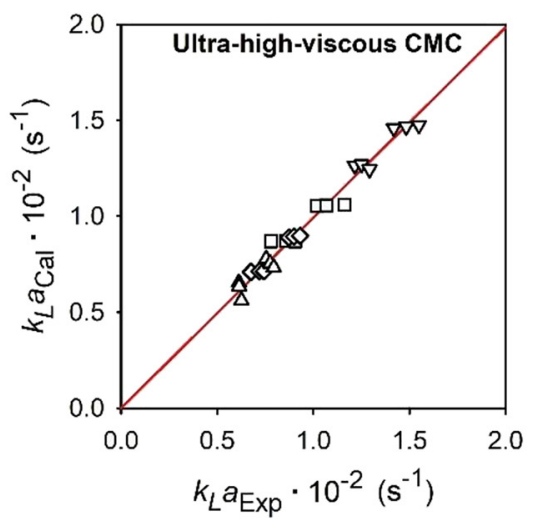

Tank B

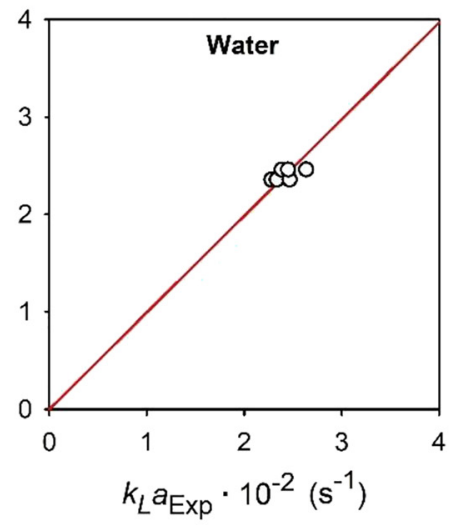

Tank B

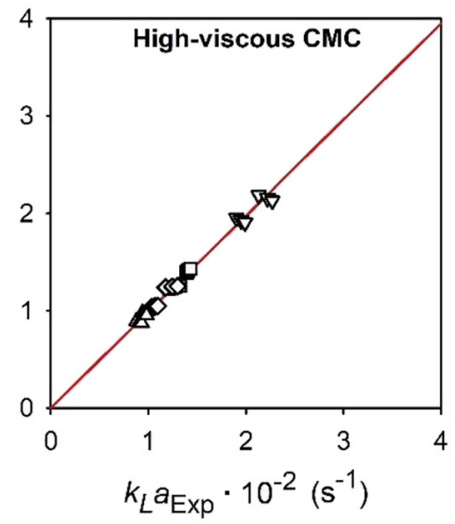

Tank B

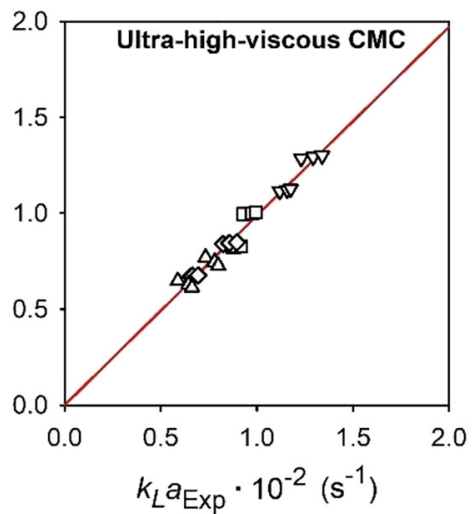

Tank C

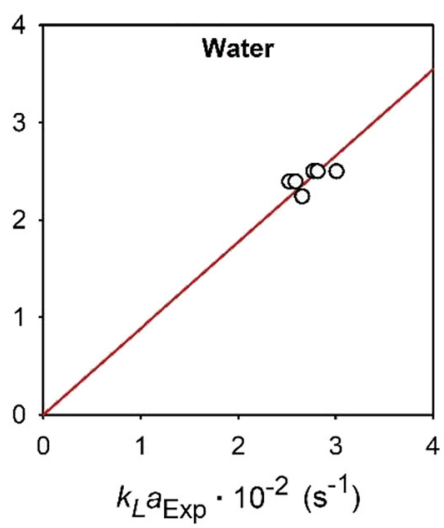

Tank C

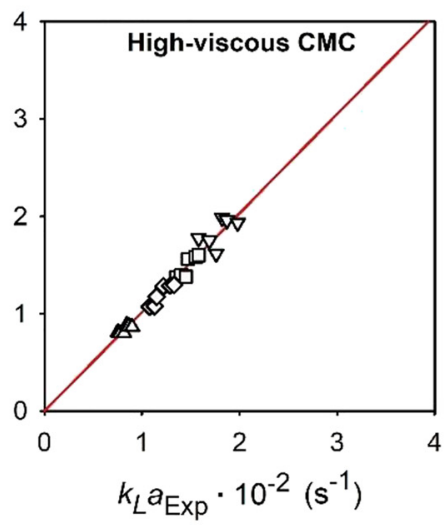

Tank C

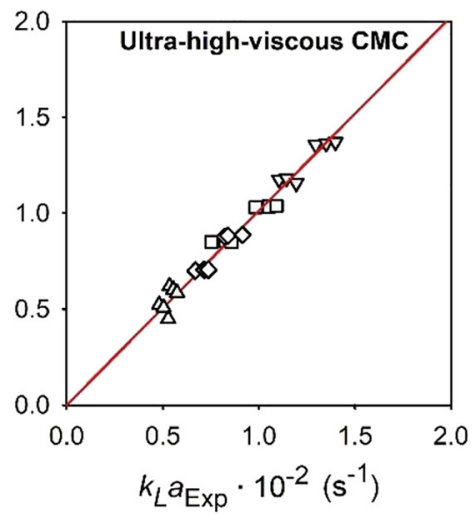

Figure 7: Comparison of calculated and experimentally determined $k_{\llcorner} a$. 
Table 4: Exponent $\left(C_{1}\right)$ and constants $(a, b$, and $c)$ for $k_{L} a$ empirical correlation. SE, standard error.

\begin{tabular}{llrrrr}
\hline Fluids & CMC polymer & $\boldsymbol{C}_{\mathbf{1}}$ & $\boldsymbol{a}$ & $\boldsymbol{b}$ & $\boldsymbol{c}$ \\
\hline Water & - & $7 \times 10^{-3}$ & 0.120 & 0.004 & -0.079 \\
CMC 0.2\% & High-viscous & $7.2 \times 10^{-6}$ & 0.122 & -0.115 & -1.829 \\
CMC 0.3\% & High-viscous & $1.2 \times 10^{-5}$ & 0.039 & 0.117 & -2.438 \\
CMC 0.4\% & High-viscous & $2.0 \times 10^{-7}$ & -0.145 & 0.051 & -4.437 \\
CMC 0.6\% & High-viscous & $2.1 \times 10^{-4}$ & -0.020 & -0.105 & -1.536 \\
CMC 0.2\% & Ultra-high-viscous & $7.4 \times 10^{-8}$ & 0.049 & 0.0515 & -3.429 \\
CMC 0.3\% & Ultra-high-viscous & $5 \times 10^{-9}$ & 0.0132 & 0.0350 & -4.829 \\
CMC 0.4\% & Ultra-high-viscous & $9.4 \times 10^{-9}$ & 0.0062 & 0.0466 & -5.446 \\
CMC 0.6\% & Ultra-high-viscous & $6.4 \times 10^{-6}$ & 0.1761 & -0.246 & -2.381 \\
\hline
\end{tabular}

\subsection{Empirical correlation}

The experimental $k_{L} a$ values reported in this work were compared to those estimated from the standard empirical correlation (Figure 7). The standard correlation for reliably predicting $k_{L} a$ in non-Newtonian fluids was defined as follows (Gabelle et al. 2011; Jamshidzadeh, Ein-Mozaffari, and Lohi 2020):

$$
k_{\mathrm{L}} a=C_{1}\left(\frac{P_{\mathrm{g}}}{V}\right)^{a}\left(U_{\mathrm{g}}\right)^{b}\left(\mu_{a}\right)^{c}
$$

where $C_{1}$ is the empirical coefficient; $a, b$, and $c$ are the empirical exponents; $P_{\mathrm{g}} / V$ is the power input per unit liquid volume $\left(\mathrm{W} \mathrm{m}^{-3}\right) ; U_{\mathrm{g}}$ is the superficial gas velocity $\left(\mathrm{m} \mathrm{s}^{-1}\right)$; and $\mu_{a}$ is apparent fluid viscosity (Pa s). The values of $C_{1}, a, b$, and $c$ were calculated using nonlinear regression analysis and are presented in Table 4. The results predicted by the empirical correlation correlated to a reasonable degree with the experimental data reported here. When the empirical correlation was used to predict $k_{L} a$ values in water, the standard errors were $15.2 \%, 10.2 \%$, and $12.4 \%$ for Tanks A, $\mathrm{B}$, and C, respectively. The empirical correlation predicted our findings quite well in the case of high-viscous CMC; the standard errors were $7.8 \%, 4.6 \%$, and $7.2 \%$ for Tanks A, B, and $C$, respectively. The standard errors decreased to $4.5 \%$ (Tank A), 4.2\% (Tank B), and 3.8\% (Tank C) for ultra-highviscous CMC. These results indicate that the empirical correlation depends on tank size (scale). The empirical correlation cannot predict $k_{L} a$ for all experimental data (Tanks A, B, and C) with the same values of coefficients and exponents. Thus, the correlation must be modified to include the effects of tank size or scale on mass transfer.

\section{Conclusions}

The presents study investigated the effects of geometric parameters on $k_{L} a$ using three stirred tanks with different sizes and geometries. The $k_{L} a$ values in shear-thinning fluids were estimated from the logged data of DO concentration. The effects of rheology and operating conditions on $k_{L} a$ were measured. The results of $k_{L} a$ obtained in this work were then compared to previously published experimental data and empirical correlation calculations.

Rheology significantly affected $k_{L} a$, since a significant decrease in $k_{L} a$ was observed in viscous shear-thinning fluids. CMC concentration and polymer type also influenced $k_{L} a$. An increase in CMC concentration decreased $k_{L} a$ considerably. High-viscous CMC resulted in a $k_{L} a$ that was two times higher than that in ultra-high-viscous CMC. However, the $k_{L} a$ values changed only slightly at higher CMC concentrations ( 0.4 and $0.6 \%$ ) because of the reduced driving force once the system reached a limit. A significant decrease in $k_{L} a$ was observed as tank size increased. The value of $k_{L} a$ in Tank A was higher than those in Tanks B and C. The higher number of impellers in Tank $C$ substantially improved $k_{L} a$ by increasing turbulence. Increasing the operating conditions $\left(N_{\mathrm{S}}\right.$ and $\left.Q\right)$ increased $k_{L} a$, and $N_{\mathrm{S}}$ impacted $k_{L} a$ more significantly than $Q$. High operating conditions increased bubble breakage, which consequently enhanced $k_{L} a$. The effect of operating conditions on $k_{L} a$ was high at low CMC concentrations but small at high CMC concentrations. The $k_{L} a$ values obtained in this work align closely with those found with our laboratory (Ali and Solsvik 2020) and pilot-scale (Ali and Solsvik 2021) stirred tanks. However, they differ significantly to the findings of other published experimental data. Operating conditions, tank size and geometry, water quality, and polymer type (for non-Newtonian fluids) are decisive parameters that must be carefully considered when predicting $k_{L} a$ in stirred tanks. Empirical correlation calculations aligned with our experimental findings when different coefficient and exponent values were used for each stirred tank. Thus, empirical correlation calculations must be modified to fit all experimental data, and the same values of coefficient and exponents should be used. The 
results of the present study can be used to validate studies of computational fluid dynamics (CFD), such as the CFD-based population model (Niño et al. 2020). More detailed investigations of the effects of $H_{L / T}$ on $k_{L} a$ are needed to reliably describe the relationship between scaleup and mass transfer.

\section{Nomenclature}

\begin{tabular}{|c|c|}
\hline$a$ & empirical exponent (-) \\
\hline$b$ & empirical exponent (-) \\
\hline$c$ & empirical exponent (-) \\
\hline C & impeller clearance (m) \\
\hline$C_{t}$ & oxygen concentration in the liquid $\left(\mathrm{mol} \mathrm{L}^{-1}\right)$ \\
\hline$C_{1}$ & empirical coefficient (-) \\
\hline $\bar{C}$ & saturation concentration of oxygen $\left(\mathrm{mol} \mathrm{L}^{-1}\right)$ \\
\hline$C_{t=0}$ & oxygen concentration at $t=0\left(\mathrm{~mol} \mathrm{~L}^{-1}\right)$ \\
\hline$d$ & sparger diameter $(\mathrm{m})$ \\
\hline$D$ & stirrer diameter $(\mathrm{m})$ \\
\hline$H$ & tank height $(\mathrm{m})$ \\
\hline$H_{L}$ & liquid height (m) \\
\hline$H_{L / T}$ & aspect ratio $(-)$ \\
\hline$H_{p}$ & probe height (m) \\
\hline$k_{s}$ & Metzner constant (-) \\
\hline$k_{L} a$ & volumetric mass transfer coefficient $\left(\mathrm{s}^{-1}\right)$ \\
\hline $1 / k_{L} a$ & characteristic time (s) \\
\hline$K_{H}$ & Henry's Law constant (mol L $\left.{ }^{-1} \mathrm{~atm}\right)$ \\
\hline$N_{s}$ & stirring speed $\left(\mathrm{s}^{-1}\right)$ \\
\hline$n$ & power-law index (-) \\
\hline$P_{\mathrm{g}}$ & power input (W) \\
\hline$P_{o}$ & power number (-) \\
\hline$P_{\text {air }}$ & partial pressure of air (atm) \\
\hline$P_{\mathrm{H}_{2} \mathrm{O}}$ & partial pressure of water vapors (atm) \\
\hline$P_{\mathrm{O}_{2}}$ & partial pressure of oxygen (atm) \\
\hline$Q$ & gas flow rate $\left(\mathrm{m}^{3} \mathrm{~s}^{-1}\right)$ \\
\hline$T$ & tank diameter (m) \\
\hline$t$ & time (s) \\
\hline$U_{\mathrm{g}}$ & superficial gas velocity $\left(\mathrm{m} \mathrm{s}^{-1}\right)$ \\
\hline$V$ & liquid volume $\left(\mathrm{m}^{-3}\right)$ \\
\hline$x_{\mathrm{O}_{2}}$ & oxygen molar fraction (\%) \\
\hline
\end{tabular}

\section{Greek symbols}

$\begin{array}{ll}\dot{\gamma} & \text { shear rate }\left(\mathrm{s}^{-1}\right) \\ \tau_{p} & \text { time response of } \mathrm{O}_{2} \text { probe }(\mathrm{s}) \\ \lambda & \text { time constant of Carreau model (s) } \\ \mu_{a} & \text { apparent fluid viscosity (Pa s) } \\ \mu_{0} & \text { fluid viscosity at minimum shear rate (Pa s) } \\ \mu_{\infty} & \text { fluid viscosity at maximum shear rate ( } \mathrm{Pa} \mathrm{s})\end{array}$

Author contributions: All the authors have accepted responsibility for the entire content of this submitted manuscript and approved submission.

Research funding: The work was supported by the Research Council of Norway (Grant no. 274398).
Conflict of interest statement: The authors declare no conflicts of interest regarding this article.

\section{References}

Ali, H., and J. Solsvik. 2020. "Axial Distributions of Bubble-Liquid Mass Transfer Coefficient in Laboratory-Scale Stirred Tank with Viscous Newtonian and Non-Newtonian Fluids." Physics of Fluids 32 (12): 123308.

Ali, H., and J. Solsvik. 2021. "Bubble Hydrodynamics and Mass Transfer in Stirred Tank with Non-Newtonian Fluids: Scale-Up from Laboratory to Pilot-Scale." Physics of Fluids 33 (3): 033319.

Arjunwadkar, S. J., K. Sarvanan, P. R. Kulkarni, and A. B. Pandit. 1998. "Gas-Liquid Mass Transfer in Dual Impeller Bioreactor." Biochemical Engineering Journal 1 (2): 99-106.

Badino, A. C., M. C. R. Facciotti, and W. Schmidell. 2001. "Volumetric Oxygen Transfer Coefficients (kLa) in Batch Cultivations Involving Non-Newtonian Broths." Biochemical Engineering Journal 8 (2): 111-9.

Bandyopadhyay, B., A. E. Humphrey, and H. Taguchi. 1967. "Dynamic Measurement of the Volumetric Oxygen Transfer Coefficient in Fermentation Systems." Biotechnology and Bioengineering 9 (4): 533-44.

Bates, R. L., P. L. Fondy, and R. R. Corpstein. 1963. "Examination of Some Geometric Parameters of Impeller Power." Industrial \& Engineering Chemistry Process Design and Development 2 (4): 310-4.

Bouaifi, M., and M. Roustan. 1998. "Bubble Size and Mass Transfer Coefficients in Dual-Impeller Agitated Reactors." The Canadian Journal of Chemical Engineering 76 (3): 390-7.

Cappello, V., C. Plais, C. Vial, and F. Augier. 2020. "Bubble Size and Liquid-Side Mass Transfer Coefficient Measurements in Aerated Stirred Tank Reactors with Non-Newtonian Liquids." Chemical Engineering Science 211: 115280.

Devi, T. T., and B. Kumar. 2017. "Mass Transfer and Power Characteristics of Stirred Tank with Rushton and Curved Blade Impeller." Engineering Science and Technology, an International Journal 20 (2): 730-7.

Doran, P. M. 2013. “Chapter 8 - Mixing.” In Bioprocess Engineering Principles, edited by P. M. Doran, 255-332. Oxford: Academic Press.

Dunn, I. J., and A. Einsele. 2007. "Oxygen Transfer Coefficients by the Dynamic Method." Journal of Applied Chemistry and Biotechnology 25 (9): 707-20.

Gabelle, J. C., F. Augier, A. Carvalho, R. Rousset, and J. Morchain. 2011. "Effect of Tank Size on kLa and Mixing Time in Aerated Stirred Reactors with Non-Newtonian Fluids." Canadian Journal of Chemical Engineering 89 (5): 1139-53.

García-Ochoa, F., and E. G. Castro. 2001. "Estimation of Oxygen Mass Transfer Coefficient in Stirred Tank Reactors Using Artificial Neural Networks." Enzyme and Microbial Technology 28 (6): 560-9.

Garcia-Ochoa, F., and E. Gomez. 2009. "Bioreactor Scale-Up and Oxygen Transfer Rate in Microbial Processes: An Overview." Biotechnology Advances 27 (2): 153-76.

Garcia-Ochoa, F., and E. Gomez. 2004. "Theoretical Prediction of GasLiquid Mass Transfer Coefficient, Specific Area and Hold-Up in Sparged Stirred Tanks." Chemical Engineering Science 59 (12): 2489-501. 
García-Ochoa, F., and E. Gómez. 1998. "Mass Transfer Coefficient in Stirred Tank Reactors for Xanthan Gum Solutions." Biochemical Engineering Journal 1 (1): 1-10.

Gogate, P. R., and A. B. Pandit. 1999. "Survey of Measurement Techniques for Gas-Liquid Mass Transfer Coefficient in Bioreactors." Biochemical Engineering Journal 4 (1): 7-15.

Grenville, R. K., and A. W. Nienow. 2003. "Blending of Miscible Liquids." In Handbook of Industrial Mixing, 507-42. Oxford: Academic Press.

Heijnen, J. J., K. V. Riet, and A. J. Wolthuis. 1980. "Influence of Very Small Bubbles on the dynamic $k_{L} A$ Measurement in Viscous GasLiquid Systems." Biotechnology and Bioengineering 22 (9): 1945-56.

Humphrey, A. 1998. "Shake Flask to Fermentor: What Have We Learned?” Biotechnology Progress 14 (1): 3-7.

Imai, Y., H. Takei, and M. Matsumura. 1987. "A Simple $\mathrm{Na}_{2} \mathrm{SO}_{3}$ Feeding Method for $K_{L} a$ Measurement in Large-Scale Fermentors." Biotechnology and Bioengineering 29 (8): 982-93.

Jamshidzadeh, M., F. Ein-Mozaffari, and A. Lohi. 2020. "Experimental Analysis of the Mass Transfer Coefficient and Interfacial Area in an Aerated Coaxial Mixing System Comprising a Non-Newtonian Solution.” Industrial \& Engineering Chemistry Research 59 (49): 21530-47.

Jaszczur, M., and A. Młynarczykowska. 2020. "A General Review of the Current Development of Mechanically Agitated Vessels." Processes 8 (8): 982.

de Jesus, S. S., J. Moreira Neto, and R. Maciel Filho. 2017. "Hydrodynamics and Mass Transfer in Bubble Column, Conventional Airlift, Stirred Airlift and Stirred Tank Bioreactors, Using Viscous Fluid: A Comparative Study." Biochemical Engineering Journal 118: 70-81.

Kazemzadeh, A., C. Elias, M. Tamer, A. Lohi, and F. Ein-Mozaffari. 2020. "Mass Transfer in a Single-Use Angled-Shaft Aerated Stirred Bioreactor Applicable for Animal Cell Culture." Chemical Engineering Science 219: 115606.

Linek, V., P. Beneš, and V. Vacek. 1989. "Dynamic Pressure Method for $k_{L} a$ Measurement in Large-Scale Bioreactors." Biotechnology and Bioengineering 33 (11): 1406-12.

Linek, V., P. Beneš, V. Vacek, and F. Hovorka. 1982. "Analysis of Differences in $k_{L} a$ Values Determined by Steady-State and Dynamic Methods in Stirred Tanks." The Chemical Engineering Journal 25 (1): 77-88.

Linek, V., M. Kordač, M. Fujasová, and T. Moucha. 2004. “Gas-Liquid Mass Transfer Coefficient in Stirred Tanks Interpreted Through Models of Idealized Eddy Structure of Turbulence in the Bubble Vicinity." Chemical Engineering and Processing: Process Intensification 43 (12): 1511-7.

Linek, V., M. Kordač, and T. Moucha. 2005. “Mechanism of Mass Transfer from Bubbles in Dispersions Part II: Mass Transfer Coefficients in Stirred Gas-Liquid Reactor and Bubble Column.” Chemical Engineering and Processing: Process Intensification 44 (1): 121-30.

Liu, B., Q. Xiao, P. Gao, B. Sunden, and F. Fan. 2020. “Investigation of Gas-Liquid Dispersion and Mass Transfer Performance of WideViscosity-Range Impellers in Water Solutions of Xanthan Gum." Chemical Engineering Research and Design 154: 60-9.

Liu, B., Q. Xiao, N. Sun, P. Gao, F. Fan, and B. Sunden. 2019. “Effect of Gas Distributor on Gas-Liquid Dispersion and Mass Transfer
Characteristics in Stirred Tank." Chemical Engineering Research and Design 145: 314-22.

Metzner, A. B., and R. E. Otto. 1957. "Agitation of Non-Newtonian Fluids." AIChE Journal 3 (1): 3-10.

Michelin, M., A. M. de Oliveira Mota, M. L. T. M. Polizeli, D. P. da Silva, A. A. Vicente, and J. A. Teixeira. 2013. "Influence of Volumetric Oxygen Transfer Coefficient $\left(k_{L} a\right)$ on Xylanases Batch Production by Aspergillus niger Van Tieghem in Stirred Tank and InternalLoop Airlift Bioreactors." Biochemical Engineering Journal 80: 19-26.

Muller, F. L., and J. F. Davidson. 1992. "On the Contribution of Small Bubbles to Mass Transfer in Bubble Columns Containing Highly Viscous Liquids." Chemical Engineering Science 47 (13-14): 3525-32.

Nauha, E. K., O. Visuri, R. Vermasvuori, and V. Alopaeus. 2015. “A New Simple Approach for the Scale-Up of Aerated Stirred Tanks." Chemical Engineering Research and Design 95: 150-61.

Nere, N. K., A. W. Patwardhan, and J. B. Joshi. 2003. "Liquid-phase Mixing in Stirred Vessels: Turbulent Flow Regime." Industrial and Engineering Chemistry Research 42 (12): 2661-98.

Niño, L., R. Gelves, H. Ali, J. Solsvik, and H. Jakobsen. 2020. "Applicability of a Modified Breakage and Coalescence Model Based on the Complete Turbulence Spectrum Concept for CFD Simulation of Gas-Liquid Mass Transfer in a Stirred Tank Reactor." Chemical Engineering Science 211: 115272.

Nishikawa, M., M. Nakamura, K. Hashimoto, and M. Nishikawa. 1981. "Gas Absorption in Aerated Mixing Vessels with Non-Newtonian Liquid." Journal of Chemical Engineering of Japan 14 (3): 227-32.

Petříček, R., T. Moucha, F. J. Rejl, L. Valenz, J. Haidl, and T. Čmelíková. 2018. "Volumetric Mass Transfer Coefficient, Power Input and Gas Hold-Up in Viscous Liquid in Mechanically Agitated Fermenters. Measurements and Scale-Up." International Journal of Heat and Mass Transfer 124: 1117-35.

Prasher, B. D., and G. B. Wills. 1973. "Mass Transfer in an Agitated Vessel.” Industrial \& Engineering Chemistry Process Design and Development 12 (3): 351-4.

Puthli, M. S., V. K. Rathod, and A. B. Pandit. 2005. "Gas-Liquid Mass Transfer Studies with Triple Impeller System on a Laboratory Scale Bioreactor." Biochemical Engineering Journal 23 (1): 25-30.

Scargiali, F., A. Busciglio, F. Grisafi, and A. Brucato. 2010. "Simplified Dynamic Pressure Method for $k_{L} a$ Measurement in Aerated Bioreactors." Biochemical Engineering Journal 49 (2): 165-72.

Scargiali, F., R. Russo, F. Grisafi, and A. Brucato. 2007. “Mass Transfer and Hydrodynamic Characteristics of a High Aspect Ratio SelfIngesting Reactor for Gas-Liquid Operations." Chemical Engineering Science 62 (5): 1376-87.

Shetty, S. A., M. V. Kantak, and B. G. Kelkar. 1992. “Gas-Phase Backmixing in Bubble-Column Reactors." AIChE Journal 38 (7): 1013-26.

Taghavi, M., R. Zadghaffari, J. Moghaddas, and Y. Moghaddas. 2011. "Experimental and CFD Investigation of Power Consumption in a Dual Rushton Turbine Stirred Tank." Chemical Engineering Research and Design 89 (3): 280-90.

Tecante, A., and L. Choplin. 1993. "Gas-Liquid Mass Transfer in NonNewtonian Fluids in a Tank Stirred with a Helical Ribbon Screw Impeller." The Canadian Journal of Chemical Engineering 71 (6): 859-65. 